\title{
The potential demand for carsharing from university students: an Italian case study
}

\author{
Romeo Danielis, Lucia Rotaris, Andrea Rusich, Eva Valeri \\ Dipartimento di Scienze Economiche, Aziendali, Matematiche e Statistiche, Università degli Studi di Trieste \\ Corresponding author: danielis@units.it
}

\begin{abstract}
The paper presents a methodology to estimate the potential demand for carsharing from university students. The methodology is based on two surveys: a paper-and-pencil questionnaire and a detailed computer-assisted interview. The data collected are used to operationalize a model that estimates the generalized cost under alternative scenarios, with and without carsharing. A Monte Carlo simulation procedure is used to estimate the probability that a person would use carsharing. The methodology has been tested with the students enrolled at the University of Trieste. The main finding is that, under the prevailing conditions, $32 \%$ of the sample students would benefit in terms of generalised cost from the use of carsharing if private car was unavailable. The model is also used to perform scenario analysis.
\end{abstract}

Keywords: carsharing, transport modeling, demand estimation, Monte Carlo simulation, university students

\section{Introduction}

Carsharing (CS) is credited to provide users with greater flexibility than public transit and per-day rental cars and to enable them to travel longer distances than they can by foot, bicycle or taxi (Millard-Ball et al., 2005). CS is deemed to provide "mobility insurance" to users while they can still satisfy their daily travel needs also via other modes. As a result, CS appears to encourage individuals to avoid purchasing new private cars or to sell cars they currently have (Millard Ball et al. 2005; Cervero et al. 2007). This reduces the demand for new automobiles and has the potential 
to decrease the overall parking provided. It is also argued that CS users have greater incentives to "trip-chain" and reduce impulsive trips because CS highlights the costs per car trip. In fact, it has been shown that members of CS programs drive significantly less than non-members (Shaheen et al., 2004; Cervero and Tsai, 2004; Cervero et al., 2007). Not least important, CS allows members to save money otherwise spent on car ownership costs (Millard-Ball et al., 2005; Danielis et al., 2014). Moreover, according to Schaefers (2013), besides the utilitarian motives of value-seeking and convenience, CS is also motivated by symbolic lifestyle and altruistic environmental motives.

It follows that, from social point of view, CS can have a positive impact on vehicle kilometers travelled, on air emissions, on car ownership levels, and the parking space needed, potentially contributing to a more sustainable transport system (Shaheen et al. 2006, Cervero et al. 2007; Lane 2005; Cervero and Tsai 2004; Cervero 2003; Martin et al., 2010, Stasko et al., 2013).

Thanks to these features, CS is rapidly growing in many countries and cities around the world. In Italy, CS is offered since two decades in many large and small cities by public, private-public or fully private organizations. Particularly successful has been the introduction in Milan in 2013 of the free-floating system by Car2Go. Other companies such as Enjoy (a joint company by Fiat, Trenitalia and Eni), Twist by VW and Drivenow by Bmw followed suit, in Milan, Rome and Florence. In most cases, companies reported rapidly increasing CS membership and use.

As the market for CS develops, various questions, relevant both to the CS organizations and to policy makers, are still unanswered such as: what is the potential demand for CS, how does the demand react to CS price changes or to the CS vehicle density, which segments of the population are most likely to use it.

Unfortunately, so far the ability of transport economists and modelers to predict the demand for CS has been limited. The section on the literature review will further discuss and elaborate this statement. In our view, providing good answers to these questions is difficult for a number of reasons.

First of all, the demand for CS is highly dependent on the mobility patterns. These patterns are partly recurrent (such as work or study commuting) and partly non-recurrent.

Second, owning one or more cars is often a group or family decision. The choice might then be between owing a second or third family car and using CS.

Third, a personlgroup of people might use jointly many modes of transport or vehicles: the car, the bicycle, the motorbike, the bus, the train, the taxi, the CS vehicle, the rent car, the airplane or walk, depending on the trip distance, trip purpose, weather, physical status, and so on. Of course, the decision of whether to use CS or not depends on the cost and quality of the supply of the other competinglcomplementary modes. Among these, public transport seems to play a crucial role: one forgoes buying a private car only if public transport is adequate. The model that predicts CS use should somehow incorporate all the above information.

Moreover, the existing studies have shown that various, quite different CS market segments exist: residents, students, tourists, customers making short-term trips or out-of-town trips; each segment have specific demand characteristics. This paper will focus on the college students segment. 
In predicting the potential demand for CS ideally, all these issues should be dealt with. Moreover, making the task even more difficult, the demand and the supply for CS should be taken jointly into account, not only for the obvious reason the two interact in the marketplace setting the price of the service but also because they interact from a technological point of view especially when the oneway CS is available. As Jorge and Correia (2013) discuss at length, in a one-way system the user determines where the CS vehicles are parked, unless a costly repositioning system is operated. Consequently, the availability of a CS car and the time needed to access a CS vehicle is not predicable, thus influencing the individual's demand for the CS.

Finally, the CS systems are quite new, there are many types of firm offering the service (nonprofit organizations, commercial firms, subsidiaries of car manufactures, car renting firms, public transport firms), who have little experience and still in search for a viable and profitable business model.

For all these reasons, modelling demand for CS is a quite challenging topic.

The demand for CS can be studied distinguishing between different market segments such as neighborhood, business, low-income, commuters, tourists (Danielis et al., 2012), and college students. With reference to these last segment, it is reported that many colleges around the world have promoted $\mathrm{CS}^{1}$, taking advantage also of the fact younger drivers appear to hold positive attitudes towards alternatives to vehicle ownership (Kuhnimhof, 2010). Identifying the potential demand for CS from students is crucial both for the firms, public andlor private, who should invest in organizing such a service and for public institutions, like the universities, who could set up policies andlor incentives to promote CS (Zheng et al., 2009; Zhou, 2014). However, as Celsor and Millard-Ball (2007) argue, carsharing planning has historically taken place through trial and error, without the benefit of clear guidelines.

This paper presents a methodology to estimate the potential demand for CS, focusing on students enrolled at the University of Trieste, located in densely populated areas of Trieste, a city suffering from huge parking congestion.

The methodology is based on two surveys: a paper-and-pencil questionnaire to be administered to a sample of students as large as possible, and a detailed computer-assisted interview to be administered to a selected number of students. The data collected are used to operationalize a model which estimates the generalized cost (GC) under alternative scenarios, with and without CS. A Monte Carlo simulation procedure is then used to estimate the probability that a person would use CS. If the methodology proves successful, it can assist CS planners and university transportation managers and help them to select appropriate marketing, operations, and pricing strategies. The methodology can be applied to other market segments as well.

This paper reviews the literature in Section 2, presents the methodology used to estimate the students' demand in Section 3, describes the sample discusses the results in Section 4, and draws some conclusions in Section 5.

\footnotetext{
${ }^{1}$ See Zipcar (2013), with reference to the United States and Rotaris and Danielis (2014) for some Italian examples (2014).
} 


\section{Review of the literature}

The literature on modeling, simulating and forecasting the potential demand for CS is not, to our knowledge, abundant. We will discuss some studies dealing the estimation of the potential demand for CS in general, not specifically for the college students segment.

A pioneering paper is the one by Schuster et al. (2005). They set up a Monte Carlo simulation of the economic decision to own or share a car based on major cost components and past car use. Many variables enter into the model such as: CS membership cost, own car cost, mileage cost, depreciation, car age, purchase price, insurance, registration, financing, repairs, CS time cost, hourly fee, travel time, number of trips, time at destination, route time, and per mile cost/fee. They apply the model to the city Baltimore, Maryland. They estimate that the percentage of cars that would be cheaper to share rather than to own, range from $4.2 \%$, for the traditional neighborhood CS model, to $14.8 \%$, for a commuter-based CS model. In a city of a million people, assuming a $50 \%$ car ownership ratio, it would amount to between 21 to 74 thousand shared cars, which is a very large number compared with the current empirical evidence. The main limitations of Schuster $e t$ al.'s model are, in our view, the choice of focusing on cars instead of individuals, the almost exclusive consideration of the monetary costs disregarding the role played by the non-monetary factors, the limited detail of the data on travel patterns, the lack of consideration of socio-economic characteristics of the decision makers.

Another major research effort it the one provided by Duncan (2010) who seeks to quantify the market potential of CS in the San Francisco Bay Area, defined as its ability to provide cost savings to those who adopt it in favor of car ownership. Two research questions are investigated: a) what kind of car usage patterns can CS accommodate in a cost effective manner; and b) how many cars have driving patterns that meet the threshold at which CS becomes less expensive than auto ownership and how many households own such a car. The 2000 Bay Area Travel Survey is used to address this question. The methodology comprises the following steps. Initially, the cost assumptions for CS and car ownership are discussed. Then, the driving dimensions are identified regarding the distance traveled, the length of time spent driving and dwelling, and the driving frequency both for work and non-work travels. Finally, based on the observed car ownership levels and travel patterns in the San Francisco Bay Area, a rough estimated of the number of ownership or households who could financially benefit from CS is estimated. Non-monetary considerations are then added to further filter out the people which, based on socio-economic considerations (availability of more than a car per driver or in the household, children in the household, availability of a SUV or a collector's car), are not "inclined" for CS. The figures that Duncan obtains are also huge. A third of Bay Area households, that is more than 800,000 households, are estimated to have at least one car with a usage pattern that is economical compatible with CS. This, combined with the quarter million Bay Area households that do not own a car, makes an impressive number (about a million households) of potential CS users. Since Duncan (2010) does not illustrate in detail the methodology used, nor presents the data, it is not possible to exactly understand why the estimated potential market is so different from the actual CS usage. Is it a matter of lack of CS vehicle supply or a lack of knowledge of its saving potential in the population due to insufficient promotion? A 
further explanation could be that the methodology used by Duncan (2010) is not yet complete or correctly applied, for example because some relevant variables, such as the psychological ones or the transaction costs, are not accounted for.

Ciari et al. (2011) use a completely different approach: they use an activity-based microsimulation technique for the modeling of CS demand. The model is implemented via an existing multi-agent, activity-based, travel demand simulator called MATSim. The simulator allows a synthetic population which reflects census data to act as in a virtual word which reflects the existing infrastructures, the available transport services and activity opportunities. Each agent has its daily activity plan which sthe tries to perform optimally according to a utility function that defines what is useful for an agent. The model is applied to part of the Zurich city center. The aggregate results match what is happening in reality. Defining the modal split as the percentage of trips travelled with a certain mode disregarding the distance, the share of agents using CS in the simulation is $0.6 \%$. An estimate for the simulated area can be obtained from a national study on CS usage leads to an estimate of $0.5 \%$ of the trips.

So far, we have discussed the contribution to estimating the demand for CS via simulation models.. An alternative approach is to use discrete choice modelling, based on stated or revealed preference data, to estimate the choice probability that CS is chosen among the alternative modes available. Catalano et al. (2008) take such an approach and apply it to the city of Palermo, Italy. The respondents could choose between private car, public transport, CS, and carpooling. The model is estimated using stated preference data. The authors conclude that the CS market could vary from $5 \%$ to $10 \%$, depending from CS fare. Zheng et al. (2009) studied the potential CS market at the University of Wisconsin-Madison by using a stated preference survey. The results show that a respondent's status at the university (e.g., faculty, student, or staff) has a strong influence, even more so than socioeconomic variables such as income or car ownership, and that people's attitudes play an important role in their decision making. Furthermore, the ease of accessing a car is a critical factor. Their prediction of the CS market share is, however, unclear. Kato et al. (2011) analyze membership choice with a nested logit model. They find that car owners are more aware of CS than non-owners but, as compared to non-owners, fewer car owners have considered using CS services. A limitation of the discrete choice modelling approach is that, although very valuable to understand the decision making process and to evaluate the role played by the socio-economic characteristics in determining the demand, it does not lead to an exact quantification of the potential demand for a given area, unless it is coupled with a simulation model that uses the discrete choice model coefficients and combines them with a detailed description of the population, of its mobility patterns, and of the CS supply characteristics.

A third approach is to use geographic information systems to assess CS market potential. Celsor and Millard-Ball (2007) use this approach to analyze the geographic market segments in urban areas. They find that neighborhood and transportation characteristics are more important indicators for CS success than individual demographics of CS members. Their results indicate that low car ownership has the strongest, most consistent correlation to the amount of CS service in a neighborhood. This result might also apply to the students population.

Building on this literature, the objective of this paper is to contribute by developing a model able to estimate the demand for CS. The demand for CS can be expressed in various ways, for instance by: 
a) the number of people who would become members because they would benefit from its use; b) the number of rentals in a given period; c) the kilometers made by the CS cars. All these indicators have been used in the literature and are used in the public debate. Indicators b) and c) are probably the most relevant for the CS companies; indicator a) is the most common in the models because it is closer to the economic approach to the decision making process. The model we develop will produce a demand forecast in terms of indicator a).

As it will be described below, our model estimates the probability that a person would use CS on the bases of the generalized cost. Our approach is, then, similar to Duncan (2010) and not to Schuster et al. (2005) who estimate the decision of whether to own or share a car. Ciari et al. (2011) used the utility function approach.

Differently from the previous models, our model will take into account that a person uses many modes of transport to satisfy his her mobility needs, and that sometimes travels with friends or family in order to share hislher travel expenses.

Our model will also incorporate many more psychological costlbenefit components and transaction costs than the previous models, for instance, the nuisance cost of maintaining and refueling the car, the pleasure of owning a car, value of the pleasure of owning a car, the pleasure of being a CS user, and many other. All the non-monetary factors were evaluated by a subset of the respondents (see below for details). The travel time and parking time has been also added to compute the overall generalized cost.

Similarly to Duncan (2010), the mobility patterns provide the starting point to estimate the generalized cost, but they are stated by the sampled respondents instead of being derived from an official survey.

The next section presents in detail the methodology used.

\section{Mobility patterns, generalized costs and the probability of using CS: an estimation methodology}

As stated in the introduction, understanding and estimating the probability that a person would use the CS is a complex issue and requires a large set of information. In our view, it requires to availability at least of the following information:

1. the person's current or hypothetical mobility pattern;

2. the modes of transport currently available to satisfy his her needs and their monetary and time costs. Of special importance is to know:

- the public transport modes available (and their monetary and time costs) if the person foregoes the use or the ownership of a private car, given that CS is often combined with public transport use; 
- the current costs of using a private car, with special attention to the availability and cost of a private garage or off-street parking at home or at trip destination;

3. the characteristics of the CS that could be offered at the locations (home, work, leisure) of interest to the individual.

Collecting all the described information requires a long and complex interview. We opted for a simplified, more feasible data collecting approach consisting in two surveys:

- Survey 1: a paper-and-pencil questionnaire to be administered to a sample of students as large as possible;

- Survey 2: a detailed computer-assisted interview to be administered to a selected number of students.

\subsection{Survey 1}

The paper-and-pencil questionnaire consisted into two parts. A first part dealing with the socioeconomic characteristics of the interviewed such as gender, age, occupation, income, availability of a driving license, number of family members with a driving license, number of cars in the family, knowledge of what CS is, likely use of the CS, and importance attributed to the concept of sustainable mobility. A second part (Table 1 and

Table 2) in which the respondent was asked to fill information regarding the mobility patterns for daily home-college commuting and other-than- studying purposes (recreational, shopping, etc.). 
Table 1 - Current mobility patterns

\begin{tabular}{|c|c|c|c|c|}
\hline \multicolumn{5}{|c|}{ Current mobility patterns home-college during a weekly } \\
\hline Mode of transport & $\begin{array}{l}\mathrm{N}^{\circ} \text { of round trip } \\
\text { journeys }\end{array}$ & $\begin{array}{l}\text { Average distance } \\
\text { per journey }\end{array}$ & $\begin{array}{l}\mathrm{N}^{\circ} \text { of journeys made } \\
\text { with other people }\end{array}$ & $\begin{array}{c}\mathrm{n}^{\circ} \text { of accompanying } \\
\text { persons }\end{array}$ \\
\hline \multicolumn{5}{|c|}{ (2) } \\
\hline Motor bike & & & do not fill in & do not fill in \\
\hline Bus & & & do not fill in & do not fill in \\
\hline Train & & & do not fill in & do not fill in \\
\hline \multicolumn{5}{|l|}{ Taxi } \\
\hline On foot & & & do not fill in & do not fill in \\
\hline Bicycle & & & do not fill in & do not fill in \\
\hline TOTAL & & do not fill in & do not fill in & do not fill in \\
\hline \multicolumn{5}{|c|}{ Current mobility patterns other than home-college during a weekly } \\
\hline \multicolumn{5}{|c|}{ 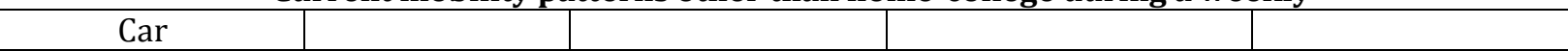 } \\
\hline Motor bike & & & do not fill in & do not fill in \\
\hline Bus & & & do not fill in & do not fill in \\
\hline Train & & & do not fill in & do not fill in \\
\hline \multicolumn{5}{|l|}{ Taxi } \\
\hline On foot & & & do not fill in & do not fill in \\
\hline Bicycle & & & do not fill in & do not fill in \\
\hline TOTAL & & do not fill in & do not fill in & do not fill in \\
\hline
\end{tabular}

Table 2 - - Most likely mobility patterns without a car and with the availability of a CS service Current mobility patterns home-college during a weekly

\begin{tabular}{|c|c|c|c|c|}
\hline Mode of transport & $\begin{array}{c}\mathrm{N}^{\circ} \text { of round } \\
\text { trip journeys }\end{array}$ & $\begin{array}{c}\text { Average distance } \\
\text { per journey }\end{array}$ & $\begin{array}{c}\mathrm{N}^{\circ} \text { of journeys made } \\
\text { with other people }\end{array}$ & $\begin{array}{c}\mathrm{n}^{\circ} \text { of accompanying } \\
\text { persons }\end{array}$ \\
\hline Motor bike & & do not fill in & do not fill in \\
\hline Bus & & & do not fill in & do not fill in \\
\hline Train & & & do not fill in & do not fill in \\
\hline Taxi & & & do not fill in & do not fill in \\
\hline On foot & & do not fill in & do not fill in & do not fill in \\
\hline Bicycle & & & do not fill in & do not fill in \\
\hline Carsharing & & & do not fill in & do not fill in \\
\hline TOTAL & & do not fill in & do not fill in \\
\hline Current mobility patterns other than home-college during a weekly \\
\hline Motor bike & & & do not fill in & do not fill in \\
\hline Bus & & & do not fill in & do not fill in \\
\hline Train & & & do not fill in & do not fill in \\
\hline Taxi & & &
\end{tabular}

As it can be seen, the respondents were requested to describe their mobility patterns under two scenarios:

- The current Scenario A_SQ, assuming that CS is not available (Table 1). Such case currently applies to the City of Trieste.

- An hypothetical Scenario B where the respondent was requested to state which would herlhis mode choices be if sthe had no private car and the CS service were available, holding constant the distance travelled (

- Table 2). 
Describing the current weekly mobility patterns was not particularly difficult for most students. Some issues were raised by the students who share a car with their parents, and from those who reside during the week in Trieste, having no car available, and in the week-ends in their hometown, with a car available and with an unpredictable mobility pattern.

Filling up Table 2, proved more difficult because the students were asked to allocate their current mobility under the hypothetical assumption that they do not have a car and that CS is available. No information was given about the costs and the availability of the shared cars in terms of their total number (density) and in how the CS works (free floating or return to the starting location). The person in charge of collecting the questionnaires provided some information and clarified some doubts, although some uncertainties remained. These difficulties should be kept in mind when assessing the validity of the estimated results.

Note that, to make the questionnaire as simple as possible, a third intermediate and more realistic scenario, with both the private car and the CS available, was not included. We preferred to force the respondents to provide us with their mobility patterns in the two extreme scenarios.

\subsection{Survey 2}

A second, much more detailed computer-assisted, face-to-face interview was administered to a selected number of people. The list of the questions asked is reported in the Appendix (Table 15 to Table 22). They encompass monetary and non-monetary costs and benefits for each of the modes considered. More realistically, three scenarios are considered (instead of two): 1) with the private car and no CS; 2) with the car and CS; 3) without the private car but with CS. The information is entered in an Excel-based program that provides an estimate of the modal and overall monetary and non-monetary costs and benefits.

The cost components considered are the following:

a) car costs $=$ monetary expenses and vehicle depreciation + opportunity cost of the garage + non-monetary costs and benefits + in-vehicle time cost.

$=\left(\right.$ depreciation cost of the $\operatorname{car}^{2}+$ fuel $\operatorname{cost}^{3}+$ maintenance cost + insurance cost + road tax + parking $\left.\operatorname{cost}^{4}\right)+($ opportunity cost of the owned garage $)+($ value of the uninsured risk that the car is stolen or damaged + nuisance cost of maintaining and refueling the car + parking searching time $\operatorname{cost}^{5}+$ value of the pleasure of owning a car + value of the pleasure of owning a car $)+\left(\right.$ in-vehicle time $\left.\operatorname{cost}^{6}\right)$.

\footnotetext{
${ }^{2}$ Based on the car purchase price, on the estimated number of years before the car value goes to zero, and on the market interest rate.

${ }^{3}$ Based on the kilometers driven collection in the mobility pattern section.

${ }^{4}$ Since the CS tariff includes parking, the cost for the use of the private car also includes parking costs.

${ }^{5}$ Based on the amount of time need to search for parking at destination and on the estimated value of parking searching time.

${ }^{6}$ Based on the distance travelled by car and on an assumed car travel speed.
} 
a) bus costs $=(\text { single ticket, } 10 \text {-ticket carnet, monthly pass or annual pass })^{7}+$ in-vehicle time cost.

b) train costs $=(\text { single ticket, by-weekly pass, monthly pass or annual pass })^{8}+$ in-vehicle time cost.

c) taxi costs $=$ taxi fares + in-vehicle time cost.

d) walking costs $=$ nonmonetary costs - nonmonetary benefits of walking + time cost.

e) bicycle costs $=$ depreciation cost of the bicycle + nonmonetary cost of cycling nonmonetary benefit of cycling + in-vehicle time cost.

f) motorbike costs $==$ depreciation cost of the motorbike + fuel cost + maintenance cost + insurance cost + road tax nonmonetary cost of riding a motorbike - nonmonetary benefit of riding a motorbike + in-vehicle time cost.

g) $\mathrm{CS}$ costs $=$ monetary costs + net nonmonetary cost + in-vehicle time cost $=($ membership fee + time fee ${ }^{*}$ distance driven $)+\left(\right.$ value of the time needed to search and reach a shared car $^{9}+$ value of the nuisance of booking a car + value of the nuisance value of not finding a car when needed + value of not having to take care of a private car + value of being a CS user) + in-vehicle time cost.

Finally, the respondent was asked to rank the three scenarios, based on the overall costs and benefits and on his $\backslash$ her preferences regarding non-surveyed variables.

Being extremely costly and time consuming (an interview lasted about one hour), we were able to administer it only to a limited number of people (50 respondents).

The information collected in this second interview provided us with the 25 costlbenefit parameters which will be used to estimate the costs and benefits for the entire sample. Table 23 in the Appendix lists them, showing the minimum, the maximum and the average value of each parameter.

\footnotetext{
${ }^{7}$ Depending on the number of rides made by the respondent the lowest figure is used, assuming rational choice decisions.

${ }^{8}$ See note above.

${ }^{9}$ From now on, it will be called access time.
} 


\subsection{The model}

Conceptually, the model used can be described as in Figure 1.

Figure 1 - Graphical illustration of the model

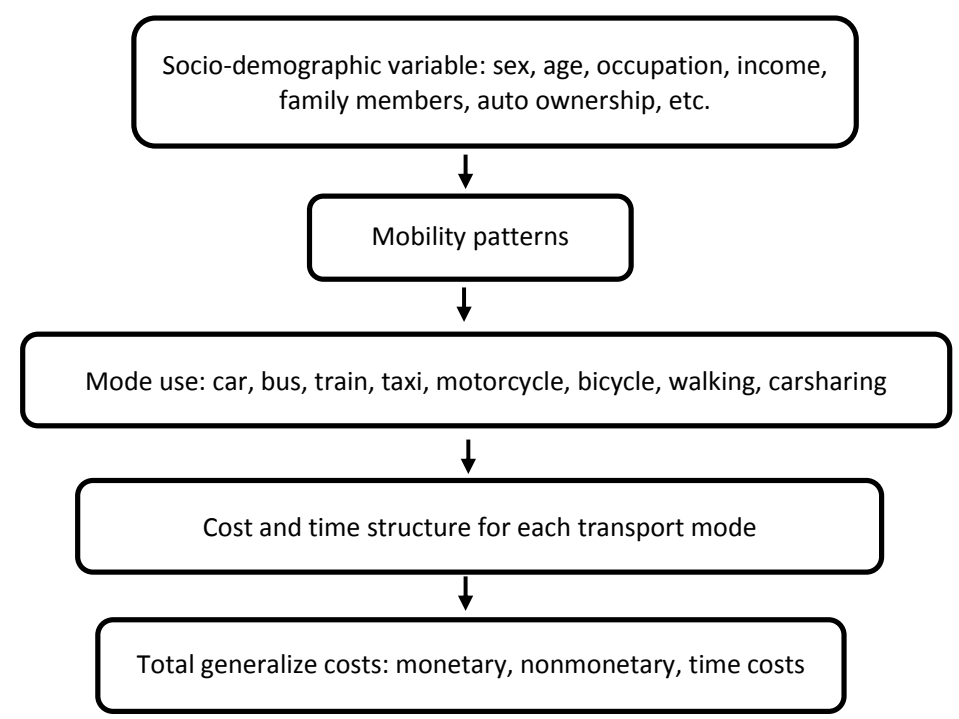

The main theoretical hypothesis underlying the model is that the probability that a person would use CS depends on the GC, evaluated when using or not using CS. Given two Scenarios, A_SQ and B, a person will use CS (and potentially do not buy or give up his lher private car) if:

$$
G C_{B}<G C_{A_{-} S Q}
$$

The calculation of each respondent's $G C_{A_{-} S Q}$ and $G C_{B}$ is performed using:

a) His \her stated mobility pattern under scenario A_SQ and B, derived from the paper-andpencil questionnaire (Survey 1);

b) His ไher VTT;

c) The costlbenefit parameters derived from the detailed, face-to-face, computer assisted interviews (Survey 2);

Since we do not know, for each respondent of the Survey 1 which are hislher own costlbenefit parameters, they are drawn via a Monte Carlo simulation procedure from the costlbenefit parameters evaluated with Survey 2, of which we know the minimum, maximum and average value. Each of the 25 unknown parameters are assumed to be triangularly distributed with the mean, lower and higher threshold derived from Survey 2. A draw is taken for each parameter and the $G C_{A_{-} S Q}$ and $G C_{B}$ are calculated. As stated, if $G C_{B}<G C_{A_{-} S Q}$, it is concluded that CS is chosen. 10,000 simulation runs are performed for each individual. The percentage of times that the generalized cost of scenario A is higher than the generalized cost of scenario B (i.e., the person is 
better off in terms of generalized costs by using CS instead of by using the private car) represents the probability that such person would use CS. That is for each individual $n$ and of each run $i=1 \ldots .10000$, the probability is calculated as:

$$
\text { Probability of using CS by person } \mathrm{n}=\frac{\sum_{i=1}^{10000} x_{i}^{n}}{10000} \quad \text { for }\left\{\begin{array}{l}
x_{i}^{n}=1 \text { if } G C^{B}<G C^{A_{-} S Q} \\
x_{i}^{n}=0 \text { if } G C^{B}>G C^{A_{-} S Q}
\end{array}\right.
$$

This procedure is applied only to those students that do state that they envisage the possibility of using CS under the conditions described in Scenario B.

The simulation was performed using the software Mathematica. The computer time needed is approximately 3 hours.

Ideally, Survey 2 should be as large as possible to collect directly from the respondents as much information as possible on the costlbenefits distributions of the various monetary and non-monetary components of the generalized cost. However, since each research effort is always time- and costconstraint and a certain degree of uncertainty is inherent in the collected data, we feel that the Monte Carlo simulation procedure illustrated above, combining information from Survey 1 and Survey 2, represents an acceptable trade-off.

As described, important characteristics of the model are that: a) it keeps into account that every individual or group of individuals uses many modes of transport to satisfy his (her mobility needs; $b$ ) it takes into account that an individual sometimes travels with friends and family; and 3) it incorporates many psychological costlbenefit and transaction cost components.

However, some important factors could not be included in the model because highly person-, modeand trip-specific. For instance, the use of the family car by a young person implies a cost that is shared by all the members of the family. We attribute a fixed percentage share to each member, although other specific family factors might determine that the cost is born only, e.g. by the father ${ }^{10}$. Travel time reliability is an important mode-specific attribute which is not included. Modes of transport such as carpooling and urban rail transport were also not considered, the latter because available only in the major cities.

Finally, one must admit that, as with many other transport choices, many rational and irrational factors affect the choice among transport modes, including monetary, regulatory, technological, psychological, and ideological ones. Consequently, the choices might not only be based on a rational generalized cost analysis and the actual decisions and the actual demand might differ from the one predicted by the simulation model. Information, habits and peer-imitation might also play a role.

\section{Results}

\subsection{Descriptive results}

\footnotetext{
${ }^{10}$ Another difficult situation to take into account is when in a family there is only one driving license so that the driver is actually satisfying not only his own but all the family mobility needs (children or even the wife).
} 
The sample was collected during the second half of 2014. The number of interviewed students was equal to 344 , equally represented by sex. 161 of the respondents (46.8\% of the total sample) state that they would not use CS in Scenario B, if no private car were available and the CS were available. They describe how they would substitute the current trips that they make by car with the bus, the bicycle or the motorcycle. Consequently, these students were excluded from the set of potential CS users. The number of students holding a driving licence is 308 (90\%). The average value of travel time (VTT) stated is €8.68.

The questionnaire asked following questions:

- What is your level of knowledge of how CS works? (1=none, 5=very good).

- Do you think you would use CS, if available in Trieste (1=definitely no, 5=definitely yes).

- How important do you consider to achieve a sustainable mobility ( $1=$ not important, $5=$ very important).

Table 3 - CS and sustainable mobility

\begin{tabular}{cccc}
\hline Ratings & Level of knowledge & Likely use & Importance of sustainable mobility \\
\hline $\mathbf{1}$ & $39 \%$ & $27 \%$ & $2 \%$ \\
$\mathbf{2}$ & $28 \%$ & $31 \%$ & $8 \%$ \\
$\mathbf{3}$ & $19 \%$ & $24 \%$ & $26 \%$ \\
$\mathbf{4}$ & $10 \%$ & $9 \%$ & $33 \%$ \\
$\mathbf{5}$ & $4 \%$ & $9 \%$ & $32 \%$ \\
\hline
\end{tabular}

The answers provided are reported in Table 3. It can be seen that the level of knowledge is not very high. More than $60 \%$ of the students did not know or hardly knew what CS was. The likely users (ratings 4 and 5) are about 18\%. The sustainable mobility concept is, on the contrary, highly regarded. An analysis of the correlations between level of knowledge and likely use or importance attributed to the sustainable mobility concept and likely use signalled that it appears to be no correlation among these variables ${ }^{11}$.

In order to evaluate if there is a need for a car, a question was asked concerning the number of cars and of driving licenses in the family. In $73 \%$ of the cases the number of driving licenses is higher than the number of cars. In $23 \%$ is lower, that is there are more cars than drivers. In $4 \%$ of the cases is equal. Consequently, there could be a demand for CS due to car unavailability.

In order to further test this hypothesis, we combine in Table 4 the answers regarding the car availability in the family and the likely use.

\footnotetext{
${ }^{11}$ Similarly, Zhou et al., (2008) found that environmental concern is not a key factor in determining people's willingness to participate in carsharing programs.
} 
Table 4 - Car availability and likely use (1=definitely no, ... 5=definitely yes)

\begin{tabular}{|lrrrrr|}
\hline Car availability & \multicolumn{5}{c|}{ Likely use } \\
\hline Less cars than driving licenses & 1 & 2 & 3 & 4 & 5 \\
\hline Number of cars equal to the number of driving licenses & $25 \%$ & $32 \%$ & $25 \%$ & $10 \%$ & $9 \%$ \\
More cars than driving licenses & $33 \%$ & $29 \%$ & $19 \%$ & $6 \%$ & $12 \%$ \\
Total & $43 \%$ & $21 \%$ & $29 \%$ & $0 \%$ & $7 \%$ \\
\hline
\end{tabular}

It is confirmed that the students with lower car availability would most probably be CS users.

An interesting analysis that our questionnaire makes it possible is the comparison among the mobility in the current (A_SQ) and the hypothetical (B) scenarios for home-college and for otherthan-home-college trips, but only for the 183 students who stated that they would use CS, either home-college and for other-than-home-college trips, if the private car were unavailable and CS were available.

Table 5 - Home-college trips

\begin{tabular}{lrrrrrrr}
\hline & \multicolumn{1}{c}{ CarlCS } & Motorcycle & \multicolumn{1}{l}{ Bus } & \multicolumn{1}{l}{ Train } & \multicolumn{1}{l}{ Taxi } & \multicolumn{1}{l}{ Walking } & \multicolumn{1}{l}{ Bike } \\
\hline Scenario A_SQ & $21.1 \%$ & $3.3 \%$ & $13.8 \%$ & $56.3 \%$ & $0.1 \%$ & $5.1 \%$ & $0.2 \%$ \\
Scenario B & $25.1 \%$ & $5.2 \%$ & $14.4 \%$ & $50.6 \%$ & $0.1 \%$ & $4.4 \%$ & $0.2 \%$ \\
Difference & $4.0 \%$ & $1.8 \%$ & $0.6 \%$ & $-5.8 \%$ & $0.0 \%$ & $-0.7 \%$ & $0.0 \%$ \\
\hline
\end{tabular}

The current home-college mobility (Table 5) relies, in terms of km, highly on the train, followed by the car and the bus. If the private cars were not available but the CS was available, the students would reduce the use of the train and substitute it with a greater use of the car $(4 \%)$, of the motorcycle (1.8) and slightly of the bus. They would also marginally reduce walking. In summary, if the CS was available the students' stated intentions would run contrary to the sustainable mobility principles. Currently, their mode choices appear to be constraint by the lack of car availability.

Table 6 - Other-than-home-college trips

\begin{tabular}{lrrrrrrr}
\hline & \multicolumn{1}{c}{ Car|CS } & \multicolumn{1}{c}{ Motorcycle } & \multicolumn{1}{l}{ Bus } & \multicolumn{1}{l}{ Train } & \multicolumn{1}{l}{ Taxi } & Walking & \multicolumn{1}{l}{ Bike } \\
\hline Scenario A_SQ & $56.7 \%$ & $4.2 \%$ & $7.2 \%$ & $23.4 \%$ & $0.2 \%$ & $7.0 \%$ & $1.2 \%$ \\
Scenario B & $45.1 \%$ & $9.7 \%$ & $11.9 \%$ & $23.4 \%$ & $0.3 \%$ & $6.5 \%$ & $3.0 \%$ \\
Difference & $-11.6 \%$ & $5.5 \%$ & $4.7 \%$ & $0.0 \%$ & $0.1 \%$ & $-0.6 \%$ & $1.8 \%$ \\
\hline
\end{tabular}

Conversely, the current other-than-home-college mobility (Table 6) relies, in terms of km, highly on the private car, followed by the train and the bus. Walking plays also an important role. Under Scenario B, CS would be used to cover $45,1 \%$ of the distance travelled (-11\%), and the use of the motorcycle, the bus, the bicycle and the taxi would also increase. In this case, hence, CS would probably have a positive effect on sustainable mobility.

\subsection{Modelling results}


The methodology described above is now applied to estimate the probability that a student would be a CS user, given herlhis mobility needs, herlhis VTT and the prevailing costs and benefits. More specifically, a comparison is made between the generalized costs under scenario A_SQ and B. The mobility patterns and the VTT are the ones indicated by the respondents in the questionnaire (Survey 1), the costs and benefits of each mode are simulated via a Monte Carlo procedure based on the information collected with Survey 2.

For each of the 183 students who consider the possibility of using CS, his ther probability of choosing CS is estimated as explained in Section 3. The decision to apply the model only to the students who stated this possibility in the questionnaire is an important one. It takes into account the respondent's knowledge and attitude - both attributes found crucial in the literature (Shaheen et al., 2006; Shaheen and Martin, 2007).

Table 24 in the Appendix reports the results for each of the 183 respondents. Under the assumption that the CS cost per minute is equal to $€ 0.29$, the sample average is equal to $60.3 \%$, equivalent to 110 students.

Collecting the estimated probabilities into 5 probability classes, one gets the results reported in Table 7.

Table 7 - Probability of using CS

\begin{tabular}{lcc}
\hline & Number of students & \% \\
\hline Stated unwillingness to use CS & 161 & $46.8 \%$ \\
Probability less than 25\% & 29 & $8.4 \%$ \\
Probability between $\mathbf{2 5 \%}$ and 50\% & 26 & $7.6 \%$ \\
Probability between 50\% and 75\% & 61 & $17.7 \%$ \\
Probability between $\mathbf{7 5 \%}$ and 100\% & 67 & $\mathbf{1 9 . 5 \%}$ \\
Total & $\mathbf{3 4 4}$ & $\mathbf{1 0 0 . 0 \%}$ \\
\hline
\end{tabular}

Of the 183 students who state that they would use CS, considering their generalized costs in the two scenarios, $19.5 \%$ have a very high probability of using it, $17.7 \%$ a good probability, $7.6 \%$ a sufficient probability and $19.5 \%$ a low probability.

It is now interesting to correlate the respondent's probability of using CS relative to some socioeconomic characteristics. We find that there is neither significant difference according to the gender nor to family income. Conversely, the level of knowledge of the CS matters. As reported in Table 8, a higher level of knowledge leads to higher probabilities of using CS. It reaches $42.9 \%$ in the wellinformed class. This result is very relevant, since CS is relatively new in Italy.

Table 8 - Probability of using CS relative to the level of knowledge of CS (1=none, ..., 5=high)

\begin{tabular}{lrrrrrr}
\hline & $\mathbf{1}$ & $\mathbf{2}$ & $\mathbf{3}$ & $\mathbf{4}$ & $\mathbf{5}$ & Total \\
\hline Stated unwillingness to use CS & $50.4 \%$ & $51.0 \%$ & $45.3 \%$ & $31.4 \%$ & $28.6 \%$ & $46.8 \%$ \\
Probability less than 25\% & $6.8 \%$ & $6.1 \%$ & $10.9 \%$ & $17.1 \%$ & $7.1 \%$ & $8.4 \%$ \\
Probability between $\mathbf{2 5 \%}$ and 50\% & $7.5 \%$ & $5.1 \%$ & $10.9 \%$ & $11.4 \%$ & $0.0 \%$ & $7.6 \%$ \\
Probability between $\mathbf{5 0 \%}$ and $\mathbf{7 5 \%}$ & $19.5 \%$ & $18.4 \%$ & $14.1 \%$ & $14.3 \%$ & $21.4 \%$ & $17.7 \%$ \\
Probability between $\mathbf{7 5 \%}$ and 100\% & $15.8 \%$ & $19.4 \%$ & $18.8 \%$ & $25.7 \%$ & $42.9 \%$ & $19.5 \%$ \\
\hline
\end{tabular}


The sensitivity to environmental issues also matters. Growing levels of importance attributed to the concept of sustainable mobility lead to higher probabilities of using CS.

Table 9 - Probability of using CS relative to the importance attributed to the goal of sustainable mobility $(1=$ none, $\ldots . .5=$ high $)$

\begin{tabular}{lrrrrrr}
\hline & $\mathbf{1}$ & $\mathbf{2}$ & $\mathbf{3}$ & $\mathbf{4}$ & $\mathbf{5}$ & Total \\
\hline Stated unwillingness to use CS & $83.3 \%$ & $51.9 \%$ & $60.7 \%$ & $40.2 \%$ & $39.1 \%$ & $46.8 \%$ \\
Probability less than 25\% & $0.0 \%$ & $7.4 \%$ & $9.0 \%$ & $7.1 \%$ & $10.0 \%$ & $8.4 \%$ \\
Probability between 25\% and 50\% & $0.0 \%$ & $14.8 \%$ & $12.4 \%$ & $23.2 \%$ & $18.2 \%$ & $17.7 \%$ \\
Probability between 50\% and 75\% & $16.7 \%$ & $7.4 \%$ & $5.6 \%$ & $6.3 \%$ & $10.0 \%$ & $7.6 \%$ \\
Probability between $\mathbf{7 5 \%}$ and 100\% & $0.0 \%$ & $18.5 \%$ & $12.4 \%$ & $23.2 \%$ & $22.7 \%$ & $19.5 \%$ \\
\hline
\end{tabular}

We also found that the absolute mobility level (in terms of the number of trips) does not univocally affect the probability of using CS and that city of residence (some students live and study in Trieste, other students live in Trieste during the week but commute back to their home town in the weeken) does not have significantly different propensities to use CS.

Another interesting piece of analysis concerns the components of the generalized total costs. The following components have been identified:

- $\quad \mathrm{MC}=$ Monetary costs of using the vehicles: in Scenario A_SQ, car, motorbike, train, bus, taxi; in Scenario B, CS substitutes the car;

- $\mathrm{D}=$ Depreciation cost of the vehicles

- $\quad$ CB_car = Non-monetary cost and benefits of owing a car;

- $\quad$ CB_moto = Non-monetary cost and benefits of using the motorbike;

- $\quad$ CB_bike $=$ Non-monetary cost and benefits of using the bicycle;

- $\quad$ B_foot = Non-monetary cost and benefits of walking;

- $\quad$ CB_CS = Non-monetary cost and benefits of using CS;

- Gara = Opportunity cost of owning a garage

- $\quad \mathrm{VTT}=$ in-vehicle travel time costs

For each respondent, the GC components resulting from the 10,000 simulative draws are retained and averaged. Next, the average values by class of probability of choosing CS are calculated. These data allow us to better understand which are the main determinants of the GC under the two scenarios.

Table 10 reports the GC components in the Scenario A_SQ. One can see that VVT is a very large component. The monetary costs of using the vehicles are half as much, followed by the depreciation cost of the vehicles. Notice also that the students place a large compensation value to the nonmonetary benefits of owning a car. The students having a larger probability of becoming a CS user have a higher (but not univocally) GCs. 
Table 10 - Components of the GC under Scenario A_SQ

\begin{tabular}{lccccccccc}
\hline prob1 & MC & D & CB_car & Gara & CB_bike & CB_moto & CB_foot & VTT & GC \\
\hline Prob. < 25\% & 4303 & 2938 & -3733 & 520 & -4 & -908 & -189 & 8499 & 11427 \\
Prob. 25-50\% & 3774 & 3987 & -3755 & 727 & -4 & -905 & -191 & 4611 & 8245 \\
Prob. 50-75\% & 3379 & 4902 & -3708 & 921 & -4 & -907 & -190 & 6894 & 11288 \\
Prob. >75\% & 3084 & 6138 & -3802 & 1170 & -4 & -906 & -189 & 8620 & 14109 \\
Total & 3336 & 5307 & -3765 & 1001 & -4 & -907 & -190 & 7682 & 12461 \\
\hline
\end{tabular}

Table 11 - Components of the GC under Scenario B

\begin{tabular}{lcccccccc}
\hline & MC & D & CB_bike & CB_moto & CB_foot & CB_CS & VTT & GC \\
\hline Prob. $<$ 25\% & 5594 & 368 & -4 & -908 & -189 & 352 & 9889 & 15102 \\
Prob. 25-50\% & 3877 & 369 & -4 & -905 & -191 & 343 & 5427 & 8917 \\
Prob. 50-75\% & 2778 & 368 & -4 & -907 & -190 & 348 & 7488 & 9881 \\
Prob. >75\% & 2185 & 368 & -4 & -906 & -189 & 528 & 6909 & 8891 \\
Total & 2799 & 368 & -4 & -907 & -190 & 443 & 7140 & 9650 \\
\hline
\end{tabular}

Table 11 reports the GC components under Scenario B. Again, the in-vehicle travel time costs are a very large component. The monetary costs of using the vehicles are much lower. The students having a lower probability of becoming CS users have large GCs, whereas the students included in the other probability classes have lower GCs.

Table 12 - Ratio among the GC components: Scenario B over Scenario A

\begin{tabular}{lrrrr}
\hline & MC & D & VTT & GC \\
\hline Prob. $<\mathbf{2 5 \%}$ & $13 \%$ & $-85 \%$ & $31 \%$ & $49 \%$ \\
Prob. 25-50\% & $-4 \%$ & $-90 \%$ & $38 \%$ & $14 \%$ \\
Prob. 50-75\% & $-23 \%$ & $-92 \%$ & $33 \%$ & $-26 \%$ \\
Prob. $>\mathbf{7 5 \%}$ & $-35 \%$ & $-94 \%$ & $-7 \%$ & $-47 \%$ \\
Total & $-25 \%$ & $-92 \%$ & $13 \%$ & $-27 \%$ \\
\hline
\end{tabular}

Table 12 reports a comparison among the largest cost components. As expected, under Scenario B (no car, with CS) the students would on average decrease their GCs by $27 \%$. The most probable users would save on average $47 \%$, the second most probable user would save $26 \%$. The remaining users would on average loose. Overall, the GC gains are due to the monetary and to depreciation costs, whereas in-vehicle travel time costs would increase.

\subsection{Simulation results}

The model is now used to simulate the impact on the probability of using CS of a change in some of the parameters. The Status Quo and 3 Scenarios are evaluated:

- Scenario Status Quo: CS costs $0.29 € /$ min (the current CS fare applied by Car2Go in Italy);

- Scenario 1: CS costs decrease to $0.19 € / \mathrm{min}$ (the current CS fare applied by Car2Go in Italy). Such a scenario might take place as a consequence of the increase competition among CS firms or thanks to a decrease in fuel costs. 
- Scenario 2: the time to access a CS car increases from the currently assumed 8 to 18 minutes. This a scenario is relevant when the CS car density decreases, for instance, in peripheral areas.

- Scenario 3: the parking time for the private car increases from the currently assumed 3 to 23 minutes. This scenario is relevant where the private parking places are much lower than the parking demand.

The results are reported in Table 13 and Table 14.

Table 13 - Impact on the average probability of using CS

\begin{tabular}{lcccc}
\hline & $\begin{array}{c}\text { Scenario SQ: } \\
\text { CS cost equal } \\
\text { to } 0.29 € / \text { min }\end{array}$ & $\begin{array}{c}\text { Scenario 1: } \\
\text { CS coste } \\
\text { qual to 0.19 } \\
€ / \text { min }\end{array}$ & $\begin{array}{c}\text { Scenario 2: } \\
\text { CS access } \\
\text { time from 8' } \\
\text { to 18' }\end{array}$ & $\begin{array}{c}\text { Scenario 2: } \\
\text { Parking time from 3' to } \\
\text { 23' }^{\prime}\end{array}$ \\
\hline $\begin{array}{l}\text { Average probability of using } \\
\text { CS }\end{array}$ & $60.3 \%$ & $68 . \%$ & $56.2 \%$ & $66.0 \%$ \\
$\begin{array}{l}\text { Corresponding Students } \\
\text { \% of total respondents }\end{array}$ & 110 & 124 & 103 & 121 \\
\hline
\end{tabular}

Table 14 - Impact on the probability of using CS by probability classes

\begin{tabular}{|c|c|c|c|c|}
\hline & $\begin{array}{l}\text { Scenario SQ: } \\
\text { CS cost equal } \\
\text { to } 0.29 € / \mathrm{min}\end{array}$ & $\begin{array}{l}\text { Scenario 1: } \\
\text { CS coste qual } \\
\text { to } 0.19 € / \mathrm{min}\end{array}$ & $\begin{array}{l}\text { Scenario } 2: \\
\text { CS access time } \\
\text { from } 8^{\prime} \text { to } 18^{\prime}\end{array}$ & 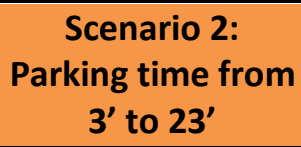 \\
\hline $\begin{array}{l}\text { Stated unwillingness to use } \\
\text { CS }\end{array}$ & $46.8 \%$ & $46.8 \%$ & $46.8 \%$ & $46.8 \%$ \\
\hline Probability less than $25 \%$ & $7.8 \%$ & $4.7 \%$ & $9.3 \%$ & $6.1 \%$ \\
\hline $\begin{array}{l}\text { Probability between } 25 \% \\
\text { and } 50 \%\end{array}$ & $8.7 \%$ & $5.8 \%$ & $10.2 \%$ & $7.0 \%$ \\
\hline $\begin{array}{l}\text { Probability between } 50 \% \\
\text { and } 75 \%\end{array}$ & $16.9 \%$ & $14.8 \%$ & $17.7 \%$ & $12.8 \%$ \\
\hline $\begin{array}{l}\text { Probability between } 75 \% \\
\text { and } 100 \%\end{array}$ & $19.8 \%$ & $27.9 \%$ & $16.0 \%$ & $27.3 \%$ \\
\hline Total & $100.0 \%$ & $100.0 \%$ & $100.0 \%$ & $100.0 \%$ \\
\hline
\end{tabular}

The average probability of using CS would increase from $60.3 \%$ to $68 \%$ if the CS costs are reduced from $0.29 € / \mathrm{min}$ to $0.19 € / \mathrm{min}$. Such an increase corresponds to 124 students ( $36 \%$ of the students interviewed). An increase in the CS access time from 8 to 18 minutes would decrease the percentage to $30 \%$ and an increase in the private car's parking time from 3 to 23 minutes increases the average probability to $35 \%$.

The more detailed information about the impact on the probability of using CS subdivided by probability classes is presented in Table 14 .

If the sample is representative of the student's population of the University of Trieste, who comprises about 20,000 students, a potential demand of 6,400 students is forecasted. 
The methodology presented in this paper could be extended to estimate whether or not other segments of the inhabitants of the city of Trieste would use CS. This is the next task of the research group.

\section{Conclusions}

The paper presents a methodology developed to estimate the potential demand for carsharing from university students. The methodology is based on two surveys: a paper-and-pencil questionnaire and a detailed, face-to-face, computer-assisted interview. The data collected are used to operationalize a model which estimates the GC under alternative scenarios, with and without CS. A Monte Carlo simulation procedure is used to estimate the probability that a person would use CS, under the hypothesis that such a probability depends on whether the GC are higher or lower when the CS is available instead of the car.

As stated, the main theoretical hypothesis underlying the model is that the probability that a person would use CS depends on the GC. Other important characteristics of the model are that: a) it keeps into account that every individual or group of individuals uses many modes of transport to satisfy his (her mobility needs; b) it takes into account that an individual sometimes travels with friends or family; and c) it incorporates many psychological costlbenefit components and transaction costs.

A set of findings are derived from the data collected. The main ones are the following:

- When the students were asked directly whether or not they would use CS, if available in Trieste, $18 \%$ of them answered "definitely yes" and an additional $24 \%$ of them "probably yes". Conversely, $58 \%$ of them stated they would not use CS.

- When the respondents were specifically asked to state whether they would include CS in their mode choices if the private car were not available, $53.2 \%$ of them (183 out of 344) stated that they would use it either for home-college or other-than-home-college trips. In terms of $\mathrm{km}, 25 \%$ of the home-college distance would be made by CS and $45.1 \%$ of the other-than-home-college distance.

- For the 183 students that stated a potential use, we estimated via a Monte Carlo simulation procedure whether they would find it convenient in terms of GC. It results that, under the prevailing conditions, $60.3 \%$ of them would find it convenient. This corresponds to about $32 \%$ of the sample. Given a student population of 20,000 at the University of Trieste, this would lead to a potential demand of 6,400 students.

- Scenario simulations lead us to conclude that such a percentage would vary by 2 to $6 \%$ when CS characteristics in terms of costs and car density vary or when changes occur in the private parking availability.

Although the model is complex and requires a considerable amount of data, it is still a simplified and partial representation of the real world decision choice process. As mentioned earlier, estimating the potential demand for CS is fraught with difficulties mainly because it involves both individual and family decisions, it depends on economic and ideological, rational and irrational motivations, it requires learning and adaptation (being a relatively newly available mode of 
transport) and it is strongly affected by contextual factors (owning a private garage, the availability and performance of public transport, specific origin-destination conditions). A model could not account for all these complexities. A partial approach and some simplifying assumptions are needed. The model presented in this paper makes, in our view, a reasonable compromise between the complexity of the decision making process, the need to collect survey data and the need to estimate the potential demand for CS and to simulate how it would be affected by policy and organizational changes.

\section{References}

Catalano, M., Lo Casto, B. and Migliore, M. (2008) Car sharing demand estimation and urban transport demand modelling using stated preference techniques. European Transport Trasporti Europei, 40, 33-50.

Celsor, C. and Millard-Ball, A. (2007) Where does carsharing work? Using Geographic Information Systems to assess market potential. Transportation Research Record, 1992, 61-69.

Cervero, R. (2003) City Carshare: first-year travel demand impacts. Transportation Research Record, 1839, 159-166.

Cervero, R., Golub, A., Nee, B. (2007) City Carshare: longer-term travel demand and car ownership impacts. Transportation Research Record, 1992, 70-80.

Cervero, R., Tsai, Y. (2004) City Carshare in San Francisco, California: second-year travel demand and car ownership impacts. Transportation Research Record, 1897, 117-127.

Ciari, F., Schuessler, N. and Axhausen, K. (2013) Estimation of Carsharing Demand Using an Activity-Based Microsimulation Approach: Model Discussion and Some Results, International Journal of Sustainable Transportation 7 (1), 70-84.

Danielis R., Rotaris L., Valeri E., (2012) "Car sharing for tourists", Italian Review of Economics, Demography and Statistics, 2, 103-119.

Danielis R., Rotaris L., Rusich A., Valeri E., (2014) "Understanding the demand for carsharing: lessons from Italian case studies", International Journal of Transport Economics, 3, 327360 .

Duncan, M. (2011) The cost saving potential of carsharing in a US context, Transportation, 38, 363-382.

Jorge, D., Correia, G. (2013) Carsharing systems demand estimation and defined operations: a literature review. European Journal of Transport and Infrastructure Research 13 (3), 201220.

Kato, H., Inagi, A., Igo, T. (2011) Awareness and Potential Choices of Carsharing: Comparative Analysis of Data from 7 Four Japanese Cities, presented at the 2012 TBR, Wahsington.

Kuhnimhof, T., Buehler, R., Dargay, J. (2011) A new generation. Transportation Research Record 2230, 58-67.

Lane, C.: PhillyCarShare (2005) first-year social and mobility impacts of carsharing in Philadelphia, Pennsylvania. Transportation Research Record, 1927, 158-166.

Martin, E., Shaheen, S., Lidicker, J. (2010) Impact of carsharing on household vehicle holdings. Transportation Research Record 2143, 150-158.

Nobis, C. (2006) Carsharing as key contribution to multimodel and sustainable mobility behavior: carsharing in Germany. Transportation Research Record, 1986, 89-97.

Rotaris, L., Danielis, R. (2014) La mobilità universitaria: esperienze internazionali e italiane a confronto, Rivista di Economia e Politica dei Trasporti, 2.

Schaefers, T. (2013) Exploring carsharing usage motives: A hierarchical means-end chain analysis, Transportation Research Part A 47, 69-77. 
Schuster, T., Byrne, J., Corbett, J., Schreuder, Y. (2005) Assessing the potential extent of carsharing: a new method and its implication. Transportation Research Record, 1927, 174181.

Shaheen, S., Cohen, A., Roberts, J. (2006) Carsharing in North America: market growth, current developments, and future potential. Transportation Research Record, 1986, 116-124.

Shaheen, S., Schwartz, A., Wipyewski, K. (2004) Policy consideration for carsharing and station cars: monitoring growth, trends, and overall impacts. Transportation Research Record, 1897, 128-136.

Shaheen, S.A. Martin, E. (2007) Assessing Early Market Potential for Carsharing in China: A Case Study of Beijing, Transport Sustainability Research Center, University of California, Berkeley.

Stasko, T.H., Buck, A.B., Gao, H.O. (2013) Carsharing in a university setting: Impacts on vehicle ownership, parking demand, and mobility in Ithaca, NY, Transport Policy 30, 262-268.

Zheng, J.,Scott, M. , Rodriguez, M., Sierzchula, W., Platz, D., Guo, J.Y., Adams, T.M. (2009). Carsharing in a University community: assessing potential demand and distinct market characteristics. Transportation Research Record, 2110, 18-26.

Zhou, J. (2014) Carsharing on university campus: Subsidies, commuter benefits, and their impacts on carsharing, Transportation Research Part D 32, 316-319.

Zipcar (2013) Zipcar Campus Solutions. 〈http://www.zipcar.com/universities/solutions〉

\section{Appendix}

Excel interface for data collection for the detailed, face-to-face, computer-assisted interview.

The rows in italics are generated by the software based on the previous information on the mobility patterns and on assumptions and information about the regional fares:

Table 15 - Private car costs module

\begin{tabular}{|c|c|c|}
\hline If you own a car, please answer the following questions & & \\
\hline How much does your car cost? & $\epsilon$ & \\
\hline After how many years do you think that the market value of your car be zero? & $\mathrm{n}^{\circ}$ & \\
\hline How much do you pay as a road tax? & $€$ & \\
\hline How much do you pay as insurance? & $\epsilon$ & \\
\hline How much do you the risk of uninsured theft or damage to your car? & $\epsilon$ & \\
\hline How much do you pay for the annual ordinary and extraordinary maintenance? & $\epsilon$ & \\
\hline $\begin{array}{l}\text { How much would you pay annually for avoiding the nuisance of having to care about maintain and } \\
\text { refuelling your car? }\end{array}$ & $\epsilon$ & \\
\hline What is the opportunity cost of your private garage? & $\epsilon$ & \\
\hline How much do you pay weekly for parking? & $\epsilon$ & \\
\hline How much time do you spend weekly to search for a parking place? & min. & \\
\hline How much would you pay for avoiding the nuisance of searching for 10 minutes for a parking place? & $\epsilon$ & \\
\hline How much do you rate in monetary terms the pleasure of owning a car? & $€$ & \\
\hline What is the sum that you would be willing to accept to give up your private car? & $€$ & \\
\hline Annual monetary expenses: & $\epsilon$ & \\
\hline Annual depreciation costs: & $\epsilon$ & \\
\hline Annual opportunity costs: & $\epsilon$ & \\
\hline Net nonmonetary costs (excluding the cost for the time spent in the vehicle): & $\epsilon$ & \\
\hline Total monetary and nonmonetary costs (excluding the cost for the time spent in the vehicle): & $€$ & \\
\hline
\end{tabular}


Table 16 - Motorcycle costs and benefits module

\begin{tabular}{|l|r|r|}
\hline If you own a motorcycle, please answer the following questions & $€$ \\
\hline How much does your motorcycle cost? & $\mathrm{n}^{\circ}$ & \\
\hline After how many years do you think that the market value of your motorcycle be zero? & $€$ & $€$ \\
\hline How much do you pay as a road tax? & $€$ & \\
\hline How much do you pay as insurance? & $€$ & \\
\hline How much do you the risk of uninsured theft or damage to your motorcycle? & & \\
\hline How much do you pay for the annual ordinary and extraordinary maintenance? & & \\
\hline $\begin{array}{l}\text { How much would you pay annually for avoiding the nuisance of having to care about maintain and } \\
\text { refuelling your motorcycle? }\end{array}$ & $€$ & \\
\hline How much do you rate in monetary terms the pleasure of owning a motorcycle? & $€$ \\
\hline What is the sum that you would be willing to accept to give up your private motorcycle? & $€$ & \\
\hline Annual monetary expenses: & $€$ & \\
\hline Annual depreciation costs: & & \\
\hline Annual opportunity costs: & & $€$ \\
\hline Net nonmonetary costs (excluding the cost for the time spent in the vehicle): & \\
\hline Total monetary and nonmonetary costs (excluding the cost for the time spent in the vehicle): & \\
\hline
\end{tabular}

Table 17 - Bicycle costs and benefits module

\section{If you own a bicycle, please answer the following questions}

How much does your bicycle cost?

After how many years do you think that the market value of your bicycle be zero?

How much do you rate in monetary terms the pleasure of cycling?

How much do you rate in monetary terms the nuisance of cycling?

Annual monetary expenses:

Annual depreciation costs:

Annual opportunity costs:

Net nonmonetary costs (excluding the cost for the time spent in the vehicle):

Total monetary and nonmonetary costs (excluding the cost for the time spent in the vehicle):

\begin{tabular}{|r|r|}
\hline $\mathrm{n}^{\circ}$ & \\
\hline$€$ & \\
\hline$€$ & \\
\hline$\epsilon$ & \\
\hline$\epsilon$ & \\
\hline$\epsilon$ & \\
\hline$\epsilon$ & \\
\hline$\epsilon$ & \\
\hline
\end{tabular}

Table 18 - Bus costs and benefits module

\section{If you use the bus, please answer the following questions}

Do you buy single tickets?

Do you buy the 10 tickets card?

Do you buy the monthly pass?

Do you buy the annual pass?

Total annual costs (excluding the cost for the time spent in the vehicle):

Table 19-Train costs and benefits module

\begin{tabular}{|c|c|}
\hline If you use the train, please answer the following questions & \\
\hline Do you buy single tickets? & \\
\hline Do you buy the bi-weekly pass? & \\
\hline Do you buy the monthly pass? & \\
\hline Do you buy the annual pass? & \\
\hline Total annual costs (excluding the cost for the time spent in the vehicle): & $€$ \\
\hline
\end{tabular}


If you use the taxi, please answer the following questions

Total annual costs (excluding the cost for the time spent in the vehicle):

Table 20 - Walking costs and benefits module

\section{If you walk to reach your work \non work destinations, please answer the following questions}

How much do you rate in monetary terms the pleasure of walking?

How much do you rate in monetary terms the nuisance of walking?

Net nonmonetary costs (excluding the cost for the time spent in the vehicle):

Table 21 - Carsharing costs and benefits module

\begin{tabular}{|c|c|c|}
\hline \multicolumn{3}{|l|}{ If you use the Carsharing, please answer the following questions } \\
\hline What is the annual membership fee & $€$ & \\
\hline Carsharing fee per minute & $€$ & \\
\hline (Round) Trips per year & $\mathrm{n}^{\circ}$ & \\
\hline How many minutes dolwould it take to you to reach a CS car? & $\mathrm{n}^{\circ}$ & \\
\hline How much would you pay for avoiding the nuisance of searching for 10 minutes for a CS car? & $€$ & \\
\hline How much would you pay annually for avoiding the nuisance of having to book a CS car? & $€$ & \\
\hline $\begin{array}{l}\text { How much would you pay annually for avoiding the risk of founding no CS car available when you } \\
\text { need it? }\end{array}$ & $€$ & \\
\hline How much do you rate in monetary terms the satisfaction of being a CS user? & $€$ & \\
\hline Annual monetary expenses: & $\epsilon$ & \\
\hline Net nonmonetary costs (excluding the cost for the time spent in the vehicle): & $\epsilon$ & \\
\hline Total monetary and nonmonetary costs (excluding the cost for the time spent in the vehicle): & $\epsilon$ & \\
\hline
\end{tabular}

Table 22 - Overall travel costs and benefits module

\begin{tabular}{|l|l|}
\hline Overall total & $€$ \\
\hline Total annual monetary expenses: & $€$ \\
\hline Total annual depreciation costs: & $€$ \\
\hline Total annual opportunity costs: & $€$ \\
\hline Total net nonmonetary costs (excluding the cost for the time spent in the vehicle): & $€$ \\
\hline Overall total monetary and nonmonetary costs (excluding the cost for the time spent in the vehicle): & $€$ \\
\hline
\end{tabular}


Table 23 - Assumed values of the triangularly distributed random variables ( $\min , \max , \mathrm{mean})^{*}$

\begin{tabular}{|c|c|c|}
\hline & unit & $\mathrm{T}(\min , \max$, mean $)$ \\
\hline \multicolumn{3}{|l|}{ Private car } \\
\hline Purchase cost & $€$ & $1000,22000,6100$ \\
\hline $\mathrm{N}^{\circ}$ of years before the market value goes to zero & $\mathrm{n}^{\circ}$ & $1,10,5$ \\
\hline Road tax & $\epsilon$ & $80,360,181$ \\
\hline Insurance cost & $\epsilon$ & $250,800,515$ \\
\hline Monetary value of the risk of uninsured theft or damage & $\epsilon$ & $0,2500,747$ \\
\hline Ordinary and extraordinary maintenance cost & $\epsilon$ & $100,1000,322$ \\
\hline WTP for avoiding the nuisance of maintaining and refuelling your car & $\epsilon$ & $0,600,202$ \\
\hline Opportunity cost of the private garage & $€$ & $0,1200,213$ \\
\hline Weekly parking costs & $\epsilon$ & $0,10,2$ \\
\hline Time spent to search for a parking place & $\min$. & $0,15,3$ \\
\hline Monetary value of the pleasure of owning a car & $€$ & $0,7000,1742$ \\
\hline WTA to give up the private car & $\epsilon$ & $100,5000,2267$ \\
\hline \multicolumn{3}{|l|}{ Motorcycle } \\
\hline Purchase cost & $€$ & $525,1500,1181$ \\
\hline $\mathrm{N}^{\circ}$ of years before the market value goes to zero & $\mathrm{n}^{\circ}$ & $2,5,4$ \\
\hline Road tax & $€$ & $10,35,20$ \\
\hline Insurance cost & $€$ & $56,270,174$ \\
\hline Monetary value of the risk of uninsured theft or damage & $€$ & $0,100,56$ \\
\hline Ordinary and extraordinary maintenance cost & $€$ & $50,150,95$ \\
\hline WTP for avoiding the nuisance of maintaining and refuelling the motorcycle & $€$ & $0,50,24$ \\
\hline Monetary value of the pleasure of owning a motorcycle & $€$ & $20,750,530$ \\
\hline WTA to give up the motorcycle & $€$ & $400,700,550$ \\
\hline \multicolumn{3}{|l|}{ Bicycle } \\
\hline Purchase cost & $€$ & $10,50,37$ \\
\hline $\mathrm{N}^{\circ}$ of years before the market value goes to zero & $\mathrm{n}^{\circ}$ & $0,2,1$ \\
\hline Monetary value of the pleasure of owning a bicycle & $€$ & $0,10,5$ \\
\hline Monetary value of the nuisance of cycling & $€$ & $0,0,0$ \\
\hline \multicolumn{3}{|l|}{ Walking } \\
\hline Monetary value of the pleasure of walking & $€$ & $10,500,209$ \\
\hline Monetary value of the nuisance of walking & $€$ & $0,100,49$ \\
\hline \multicolumn{3}{|l|}{ Carsharing } \\
\hline Membership fee & $€$ & $20,100,50$ \\
\hline Minutes needed to reach a CS car & $\mathrm{n}^{\circ}$ & $5,10,8$ \\
\hline WTP for avoiding the nuisance of having to book a CS car & $€$ & $20,100,61$ \\
\hline WTP for avoiding the risk of founding no CS car available when you need it & $€$ & $30,300,111$ \\
\hline Monetary value of the satisfaction of being a CS user & $€$ & $0,300,114$ \\
\hline
\end{tabular}

*Annual values unless otherwise stated.

Table 24 - Estimated individual probability of using CS

81.6\%, 8.6\%, 68.8\%, 74.4\%, 88.5\%, 70.2\%, 67.0\%, 21.9\%, 41.9\%, 84.0\%, 50.5\%, 12.8\%, 48.8\%, 15.4\%, 34.4\%, 45.1\%, $79.6 \%, 1.0 \%, 75.2 \%, 81.2 \%, 0.6 \%, 99.2 \%, 64.6 \%, 5.2 \%, 75.4 \%, 61.4 \%, 91.1 \%, 48.4 \%, 53.8 \%, 31.1 \%, 71.1 \%, 27.9 \%$, 71.2\%, 60.1\%, 56.8\%, 55.5\%, 92.6\%, 100.0\%, 30.5\%, 74.4\%, 90.4\%, 72.7\%, 81.4\%, 89.2\%, 90.5\%, 79.6\%, 14.4\%, 74.9\%, 69.7\%, 69.5\%, 85.6\%, 78.7\%, 81.0\%, 99.5\%, 21.9\%, 90.1\%, 19.8\%, 78.0\%, 45.9\%, 98.9\%, 71.9\%, 20.9\%, 85.9\%, 51.3\%, $21.6 \%, 83.6 \%, 2.1 \%, 85.6 \%, 64.1 \%, 75.5 \%, 70.5 \%, 82.4 \%, 69.5 \%, 90.5 \%, 63.2 \%, 65.3 \%, 91.7 \%, 100.0 \%, 90.5 \%, 2.8 \%$, $92.0 \%, 83.6 \%, 84.9 \%, 52.8 \%, 62.6 \%, 86.0 \%, 81.7 \%, 56.0 \%, 71.9 \%, 44.1 \%, 13.8 \%, 5.6 \%, 76.5 \%, 74.2 \%, 86.4 \%, 95.5 \%$, $0.0 \%, 61.3 \%, 72.7 \%, 32.4 \%, 77.0 \%, 52.2 \%, 6.0 \%, 89.8 \%, 85.1 \%, 22.2 \%, 18.1 \%, 77.0 \%, 31.6 \%, 95.3 \%, 83.9 \%, 63.8 \%$, 76.8\%, 56.1\%, 51.8\%, 17.7\%, 66.0\%, 51.7\%, 25.8\%, 29.1\%, 62.3\%, 80.5\%, 50.4\%, 67.1\%, 87.6\%, 73.8\%, 99.8\%, 79.7\%, $98.5 \%, 89.4 \%, 18.8 \%, 75.9 \%, 27.4 \%, 70.1 \%, 83.9 \%, 83.8 \%, 42.8 \%, 80.0 \%, 74.0 \%, 78.7 \%, 83.2 \%, 3.8 \%, 80.0 \%, 15.7 \%$, 
21.2\%, 12.8\%, 70.1\%, 33.9\%, 90.7\%, 66.9\%, 55.2\%, 71.4\%, 71.0\%, 94.4\%, 48.8\%, 61.5\%, 71.3\%, 11.8\%, 54.2\%, 42.9\%, $100.0 \%, 50.3 \%, 67.6 \%, 0.0 \%, 41.3 \%, 44.9 \%, 87.8 \%, 49.4 \%, 63.7 \%, 63.6 \%, 80.6 \%, 72.9 \%, 87.5 \%, 72.4 \%, 33.5 \%, 64.0 \%$, $69.8 \%, 68.7 \%, 38.0 \%, 23.0 \%, 75.7 \%, 32.8 \%, 45.8 \%$;

average $=60,3 \%$ 